\title{
Workers' Knowledge of their Pension Coverage: A Reevaluation
}

\author{
Martha Starr-McCluer and Annika Sundén \\ Federal Reserve Board of Governors \\ January 1999
}

Because employer-provided pensions represent an important source of income during retirement, accurate information on pension coverage would seem to be crucial for making sound decisions on retirement timing, saving and portfolio allocation. However, previous research suggests that workers' knowledge of their pension provisions is often incomplete or incorrect. This paper re-examines workers' knowledge of their pension coverage, using matched employer-employee data from the Federal Reserve Board's Survey of Consumer Finances. We find that, while most workers in our sample accurately reported the general features of their pension coverage, their knowledge of the detailed features was often fairly limited.

Please address correspondence to: Annika Sundén, Federal Reserve Board of Governors, Stop 153, Washington, D.C. 20551. Email: asunden@frb.gov. The authors are grateful to Julia Coronado, Darrel Cohen, Arthur Kennickell, Dean Maki, Olivia Mitchell, seminar participants at the Census Bureau's International Symposium on Linked Employer-Employee Data, and the editors of this volume for helpful comments, and to Kevin Moore for able research assistance. The views expressed in this paper are those of the authors, and not necessarily those of the Federal Reserve Board or its staff. 


\section{Workers' Knowledge of their Pension Coverage: A Reevaluation}

\section{Introduction}

Employer provided pensions are important sources of income during retirement, constituting a substantial fraction of household wealth. The characteristics of households' pension plans affect many decisions - from how much to work and save to when to retire. In making sound decisions about retirement income adequacy, savings, and portfolio allocation, accurate information on the characteristics of pension plans would seem to be crucial. The purpose of this paper is to examine how much knowledge workers have about their pension plans by comparing reports provided by workers to their employers' reports.

The subject of workers' knowledge of their pension coverage is particularly interesting in view of the dramatic increase in the provision of 401(k)-type plans during the last 10-15 years. These plans require workers to decide whether to participate in the plan and in the case of participation, how much to contribute to the plan. Compared to traditional defined benefit pension plans, the choices in 401(k) plans put more responsibility on the worker to plan for his or her own retirement. At the same time, the growth of 401(k) plans has prompted employers to provide more information about pension plans, and there has been an increase in financial education programs in the workplace (EBRI 1996).

In previous research using the 1983 Survey of Consumer Finances, Mitchell (1988) found that workers were fairly misinformed about the characteristics of their pensions. Bernheim (1988) studied the accuracy of knowledge of expected Social Security benefits in a sample of workers close to retirement. He found that workers formed expectations using only part of the information available to them and that the accuracy of their expectations would have been improved if all available information was used. In related research, Bernheim (1994) used survey data on financial planning collected by financial institutions and found evidence that people's financial knowledge is generally limited.

This paper reevaluates the question of workers' knowledge of their pension coverage using the 1989 Survey of Consumer Finances (SCF) linked with a Pension Provider Survey 
(PPS). The SCF collects the households' reports on their pension coverage while the PPS provide information on these plans from the employer. The linked employer-employee data provide a unique opportunity to construct a measure of validation using information both from workers and their employers. In contrast to the perhaps more common method of sampling employers first, this is a household-based survey supplemented with information from the employers of individuals in these households.

The paper is organized as follows: The next section describes the data. The third section presents descriptive statistics comparing worker and employer reports on several dimensions of pension plans such as type of plan, contribution rates, early retirement options and normal retirement age. In the fourth section of the paper we examine whether there are systematic differences across workers using a multivariate framework. The paper concludes with a discussion.

\section{Data}

The data used in this study come from the 1989 Survey of Consumer Finances (SCF) linked with a supplemental Pension Provider Survey (PPS). The SCF is a triennial survey sponsored by the Board of Governors of the Federal Reserve System in cooperation with the Statistics of Income Division at the Department of the Treasury. The most recent Pension Provider Survey was collected in 1989 - the high cost of collecting and coding the information has prohibited collection for more recent surveys.

The Survey of Consumer Finances. The purpose of the SCF is to provide information on the financial characteristics of U.S. households. To this end, the SCF collects very detailed information on households' assets, liabilities and demographic characteristics. The interviews for the SCF are conducted in person and are generally conducted with the financially most knowledgeable member of the household. Respondents are encouraged to consult records, and 30 to 40 percent do. The SCF utilizes a dual-frame sample. The first part consists of a standard multi-stage area probability sample, drawn from a file based on Census records. The second part of the sample is a "list sample" drawn from a special file of tax records. From this list, units are selected at disproportionate rates, with the sampling rate 
higher for the wealthier strata. Together the two parts of the sample are intended to provide good coverage of both broadly distributed items, such as homeownership, and items that are more narrowly held, like businesses and bonds. The response rate for the area probability sample is around 70 percent, and for the list sample the rate is about 34 percent. The 1989 survey data were collected by the Survey Research Center of the University of Michigan. The survey sample size was 3,143 households in $1989 .^{1}$

Pension Plans. The survey also includes detailed questions on households' pension coverage from their employers and the characteristics of these pension plans. Employer sponsored pensions are voluntary arrangements, where employers provide or sponsor a pension plan for their employees. Approximately 50 percent of all households have an employer provided pension plan. ${ }^{2}$ Employer provided pensions are, in principle, of two type types: defined benefit plans (DB) and defined contribution plans (DC). Participation in a DB plan is usually mandatory for the worker. The benefits in the plan are determined by a formula usually involving age, years of service, and some average of the worker's earnings. In most cases, the plan is financed through contributions from the employer, but sometimes employees also make contributions. The plan often requires that the worker remain with the firm for a minimum number of years before earning rights to the pension. Once a worker has earned rights to the benefit, he is said to be vested in the plan.

Contrary to DB plans, participation in DC plans is usually voluntary. In a DC plan, an account is established for each worker, and contributions are made to the account by employees and/or employers. The contributions are invested, and in many cases the worker can choose how to allocate the money amount among investment options. The benefit at retirement depends on contributions and the return on the investment. At retirement the worker can receive the account balance as a lump sum or convert it to an annuity. There are several types of DC-plans. One of the most common plans is a 401(k) plan, named after the tax regulation that governs the plan. In this plan workers can make contributions before taxes and thereby defer income tax on the contribution until the money is withdrawn. Another type

1. See Kennickell and Starr-McCluer (1994) for a more detailed description of the 1989 SCF.

2. In addition, almost all workers are covered by Social Security. 
of DC plan is a profit sharing plan. In this plan only employers contribute, and contributions are determined by the firm's profits. When employer sponsored plans were first introduced, most of them were DB plans. However, in the last 15 years there has been a dramatic shift from DB plans to DC plans (Hinz, et.al. 1994).

While most information in the SCF is collected at the household level, information on employment and pension coverage is collected for both respondents and their spouses. ${ }^{3}$ The section on pension coverage was revised extensively between the 1983 and 1989 SCFs. The order of the questions was rearranged and many of the questions were rewritten in order to become clearer to the respondents. Particular emphasis was put on clarifying the difference between DB and DC plans.

The Pension Provider Survey. In addition to the household survey, the 1989 SCF had a supplemental Pension Provider Survey (PPS) in which employers of households reporting pension coverage were contacted and asked to supply their pension plan's Summary Plan Description (SPD). The SPD is a legal document describing the features of the pension plan, for example, the rules governing contributions and the calculation of benefits. The information in the SPD pertains to the plan as a whole and not to a specific worker. For example, the SPD provides the rules for how contributions are calculated but not how much a specific worker contributes.

As with the household data, the employer data were collected by the Survey Research Center of the University of Michigan. In the household survey, households with pension coverage were asked to provide the name and address of their employer and to give permission for the employer to be contacted. Using this information, employers were contacted by telephone, targeting personnel departments. ${ }^{4}$ A short interview was conducted, and the employer was asked to identify pension plans covering workers in a specific occupation and work location. The household's identity was not revealed to the employer. At the end of the interview, employers were asked to submit the SPDs for their pension plans. For employers who failed to respond, recontacts were made and in addition, the U.S.

3. Spouses include couples living together with shared finances.

4. Households were not asked to provide information on a contact person at their workplace. 
Department of Labor was contacted and asked to supply missing SPDs. ${ }^{5}$

The information from these documents was coded by the Survey Research Center using a questionnaire. The data were made available as a separate file that can be merged with the household data. Among the households interviewed for the $1989 \mathrm{SCF}, 1,299$ households provided names of at least one pension provider (the sample size is reduced from 3,143 since only about 50 percent of households are covered by a pension, and among households covered not everyone provided the name of their employer). The summary plan description was obtained from 1,039 employers, and 948 plans were successfully coded. ${ }^{6}$ The number of plans in the sample is further reduced since some households are covered by the same plans. Pension plans are specific to the employer but since households were sampled without regard to which employer they work for, households in the sample could have the same employer. For this reason, the number of separate plans in the sample is further reduced to 789 .

Linking employee and employer data. The PPS data were merged with the household data. The pension information in the household data was collected for the respondent as well as for the spouse. However, we limit the sample to include information on respondents only. Because our interest is in individuals' knowledge of their pension provisions, we want to ensure that the information was reported by the individual actually covered by the plan. Confining the analysis to respondents only reduces the number of observations by about 40 percent (the numbers of men and women are reduced in about equal proportions). ${ }^{7}$

The SCF and PPS data are matched by pension plan, and in the merged data the unit of analysis is an employer plan-employee pair. This means that there are multiple observations for some respondents with multiple plans. The merged data set includes 663

5. By law, firms are required to file their SPDs with the Department of Labor.

6. The remaining 91 plans could not be coded since employers in these instances provided information on the wrong plan, the wrong document, or insufficient information.

7. In the SCF, details on pension coverage for the spouse can be reported by either the respondent or the spouse. If the spouse reported on their own coverage, we would like to include these observations in the sample. However, the 1989 SCF did not record who reported the information. Since it is not possible to determine if the spouse provided the information on their own pension plans, the sample is limited to respondents. 
observations, representing 545 individuals.

The 1989 SCF collected detailed information on up to three pension plans per respondent. If the respondent had more than one plan, he or she was asked to list the plan considered most important first. The PPS data collected information on all the plans a given worker's firm offered. For each provider, the data were organized according to type of plan: defined benefit (DB) plans were listed first, followed by defined contribution (DC) plans, and plans that had features of both DB and DC plans. The firm data did not include information that linked a specific plan to the respondent report. In order to link the reports by respondents and firms, we have to make some assumptions. Table 1 shows the number of plans reported by the firm and respondent before and after the data have been linked.

The upper half of the table presents the data before the reports have been linked. For close to 60 percent of the plans, the firm and the respondent reported an equal number of plans. The linking is obvious when the respondent and firm each reported one plan. If the respondent and the firm reported more than one plan but an equal number of plans, we use the plan type to link the reports. For example, if the respondent reported one DB plan and one DC plan, and the firm reported the same types of plans, we match the reports so that the plan type matches. The linking is less obvious in the cases when plan type does not match, for example when the respondent reported one DB plan and one DC plan and the firm reported two DC plans. For cases like this, we inspect the data (i.e. the reports on the characteristics of the plans) to match the worker and firm reports. The matching rule follows a principle of giving the respondent "the benefit of the doubt". This may introduce some bias towards workers knowing more about their pension plan than they really do.

For about 40 percent of the plan-worker matches, the respondent and the firm reported different numbers of plans. The reasons for this difference may be that the respondent reported the wrong number of plans, or that the respondent reported the correct number of plans but was not covered by all the plans that the firm offered. For example, many firms have a DB plan that covers all employees but also offer a 401(k) plan for which participation is voluntary.

The most common discrepancy is the case where the firm reported one plan and the 
worker reported being covered by two plans. ${ }^{8}$ Using the same rule of "giving the respondent the benefit of the doubt" as previously, we match the firm plan to one of the worker's reports. For 49 firms, the firm reported two plans, while the respondent only reported one plan. Within this group of firms, most reported to have one DB and one DC plan. This gives some support to the argument that firms may have a DC plan in which participation is voluntary. Again, we give the respondent "the benefit of the doubt" and linked to the plan type he or she reported. In the remaining cases where the firm and worker reports differed, the same type of rules have been used to match the data.

\section{Worker Knowledge of Pensions}

We measure workers' knowledge of their pension plans by comparing the characteristics of the plans reported by workers to those reported by firms. If the worker has complete knowledge about his or her pension plan, these reports will be identical. Note, however, that the firm reports were coded from the SPD by coders at the Survey Research Center following a questionnaire. This was a complex task, and may have been subject to coding error. Because it was not possible to measure this, we took the firm reports in the PPS file to be the "true" description of the plan.

Table 2 presents some basic descriptive statistics on the extent to which workers and firms agreed on the features of the pension plan. Since many of the decisions about DC plans require workers' involvement, we expect workers covered by a DC plan to be more likely to know about the plan, than a worker covered by a DB plan. Column 1 presents the percent of cases in which workers' and firms' reports on the pension provisions agreed. The comparison excludes cases where the worker answered "don't know" to the questions about whether they had pension coverage. ${ }^{9}$ A fairly large share of workers knew what type of plan they had-in

8. The worker may not know how many plans he is covered by, but the discrepancy could also be a reporting error. For example, although respondents are asked about Individual Retirement Accounts (IRAs) at a different point in the questionnaire and are told not to include IRAs when reporting employer-sponsored plans, experience suggests that some individuals report IRAs together with employer-sponsored plans.

9. The analysis is restricted to the sample of matched employer-employee reports. However, there may be missing data earlier in the analysis. For example, a worker who answered "don't know" 
77.5 percent of cases there was agreement. As discussed, part of the linking of employeeemployer reports relied on the pension plan type, which may have introduced some upward bias. However, the share is similar when the sample was restricted to firms and workers with only one plan, so the bias appears to be small. As expected, workers actually covered by a DC plan were more likely to know the type than workers covered by a DB plan. This differs from Mitchell's (1988) finding based on the 1983 SCF, which showed that workers with DB plans were more knowledgeable than workers with DC plans. One reason for our result may be the increase in DC plans between 1983 and 1989.

We next examine how well informed workers were about the specific features of their pension plans. We investigate this only for workers who knew what type of plan they had. For DB plans we examine knowledge about contribution information and portability. We limit contribution information to a variable indicating whether the worker contributes to the plan. The results suggest that more than three-quarters of workers were aware of the basic contribution provisions in DB-plans. The portability variable indicates whether the worker's benefit is vested. In order to determine vesting status we use the worker's report on his or her number of years with the firm. The results show that more than four-fifths of workers with a DB plan knew their vesting status.

For workers with defined contribution plans, we compare reports on type of DC plan, contribution information, liquidity of the plan and investment options. About two-thirds of workers knew the type of DC plan. Surprisingly, a lower share of workers knew whether they themselves contribute to the plan than whether their employer contributes. Less than one-third of workers knew whether it was possible to withdraw funds from the plan, while over 60 percent knew about the rules for borrowing from the plan. Information on investment options was only available from firms that allowed workers to choose how to allocate their funds. Among these workers, 66 percent were able to report what options they had chosen. The results indicate that workers who knew what type of plan they were covered by

to whether they are covered by any pension plan is not included in the matched sample; the data indicate (not shown) that very few workers fall into this category. Similarly, a worker may also report being covered by a pension plan, but the firm does not offer a plan. 
seemed to be fairly well informed about the details of the plans. Compared to earlier studies (Mitchell 1988), our results indicate similar or higher percentages of workers having information on the specific details on their plans. In order to determine knowledge of pension provisions we also need to examine the rate of missing data. There are several reasons why data may be missing: Respondents may not know the information and answer "don't know", they may not be willing to share the information and refuse an answer, or data may be missing due to coding error. We are particularly interested in the first category of missing data. For example, if a large share of workers responded "don't know" to the type of their pension plan, this would indicate limited knowledge even if the workers who did provide the information were knowledgeable about the type of plan. The shares of workers indicating "don't know" for the matched SCF-PPS data are presented in the second column of Table 2. The results show that for each type of plan, less than 2 percent of workers reported that they don't know the type of their pension plan. Among workers covered by a DB plan, the vast majority of workers could provide an answer about the characteristics of the plan. The results indicate that the rate of missing data is higher among workers with DC plans, with the exception of contribution information.

\section{A Multivariate Framework}

Next we relate worker and firm reports on the characteristics of pension plans in a multivariate framework. Following Mitchell (1988), we hypothesize that a worker's knowledge about the pension plan is related to the amount of information he or she has collected about the plan. The investment in collecting information is likely to be greater, the more a worker has to gain from the investment. On the other hand, the investment will be negatively affected by the cost of collecting information.

We define the dependent variable to be a measure of agreement, taking the value one if the firm and the worker agreed and zero otherwise. Given the discrete outcome we estimate the model using a probit specification. The explanatory variables include a vector of demographic and firm characteristics intended to capture the benefits and costs of gathering information. The closer a worker is to retirement, the more beneficial it will be to collect 
information on the structure of the pension plan. To control for age, we include an indicator variable equal to one if the worker is older than 45. A worker who expects to collect a high benefit has more to gain from collecting information on the pension plan. Since workers with high income are more likely to have high benefits, we expect income to be positively correlated with knowledge of the pension plan. In addition, the tax advantage of participating in a 401(k)-type plan is going to be larger for a high-income individual. Pension plans are often complex, and a worker's ability to process the information may also affect the likelihood of gathering information; thus, education may be positively correlated with the probability of being well informed about the pension plan. We include indicator variables for the level of education, with the omitted category being no high school degree. The longer a worker has been with the firm, the higher his expected benefit will be, so we expect tenure to have a positive effect on knowledge of the pension plan. We control for tenure by including the number of years the worker has been with the firm. Unions often provide information, so we expect union coverage to have a positive effect on knowledge. The variable for union is an indicator variable equal to one if the worker is covered by a union contract.

We hypothesize that the size of the firm will affect workers' knowledge of pension characteristics. Since there is evidence of scale economies in the administration of pension plans (Mitchell and Andrews 1981), we expect larger firms to be more likely to give seminars and produce information booklets for their workers. A firm is more likely to provide information when the pension plan is generous, and larger firms are more likely to have generous pension plans. Thus, we include a categorical variable controlling for firm size. The results from the estimation are presented in Table 3.

Type of pension plan. As expected, the level of education significantly affected the probability of knowing the type of pension plan, with college graduates being more likely than high school dropouts to know the type of plan. The size of the firm also significantly affected the likelihood of knowing the type of plan, supporting our hypothesis. Mitchell (1988) found no significant effect of firm size variables on knowledge of type of pension plan. Surprisingly, age did not have a significant effect. Women were neither more nor less likely than men to know the type of their pension plan. 
Among workers who know the type of their plan, we next examine how well informed they are about the characteristics of their plan.

Defined Benefit Plans. We examine two plan features for workers with DB plans: employee contributions and portability. ${ }^{10}$ In the equation for contribution information, only gender had a significant effect: women were less likely to know the contribution information. One explanation for the lack of systematic difference in knowledge among workers may be that under DB plans, provisions for contributions are often mandatory. As expected, individuals with long tenure were more likely to know whether they were vested in the pension plan.

Defined Contribution Plans. For DC plans we examine knowledge of type of DC plan, contribution information and the possibilities of withdrawing or borrowing funds from the plan. The SCF collected information on type of DC plan, i.e. whether it is a 401(k)-plan, thrift/savings plan, profit sharing plan, ESOP, or a traditional DC plan like TIAA-CREF. As expected, workers in large firms were more likely to know the type of DC plan. The results indicate that older workers were more likely to know the type of plan. In contrast workers with longer tenure were less likely to know the type of plan. Unionized workers and women were also less likely to know the type of plan. Knowledge of the type of DC plan may be a fairly subtle distinction to workers which may explain the results.

Workers older than age 45 were more likely to know whether they contributed to the plan, while tenure had a negative effect on knowledge. Older workers are closer to retirement and therefore more likely to care about their retirement income. On the other hand, tenure had a negative effect on knowledge of contribution. This may be due to the fact that DC plans with employee contribution such as $401(\mathrm{k})$ plans, were a relatively new phenomenon in 1989, and many workers with long tenure had only participated for a fairly short time; for these workers, possible coverage by defined benefit plans was likely to be more important.

10. The SCF also collects information on expected benefits and expected retirement age. However, these reports are hard to interpret and compare to firms' reports since the expected benefit and retirement age reported by the worker are based on a vast number of assumptions about future labor force participation and salary growth. We therefore limit the analysis to characteristics that are more straightforward to measure. 
As previously, workers in larger firms were more likely to be well informed, consistent with greater information provision by larger firms. The result is also consistent with Mitchell's (1988) findings. Surprisingly, income had a negative effect on knowledge.

Similar effects can be found in the model for agreement on employer contribution, although here it is interesting to note that firm size did not have a significant effect on knowledge of employer contribution. This may reflect the type of financial education programs firms offered. Programs are often targeted towards how the worker should prepare for retirement and may emphasize the choices the worker has to make rather than the features of the employer side.

Some DC plans, in particular 401(k) plans, offer some kind of liquidity in that they allow the worker to borrow funds or to withdraw the funds if in financial need. As 401(k) plans become more common, one concern is that workers will be tempted to use their retirement funds for other purposes. In the SCF-PPS data, only a small fraction of workers could actually withdraw funds from their DC plans but that almost half could borrow. However, workers were fairly uninformed about these features. Few variables had any explanatory power in these regressions. Workers with long tenure were less likely to know about the possibility of borrowing funds from their plan. For these workers retirement is drawing closer, and they may see less need to borrow from their retirement plan than younger workers who have a longer time to repay the loan.

\section{Conclusions}

This paper has examined workers' knowledge of their pension provisions using linked employee-employer data from the 1989 SCF and PPS. While questions are often raised about workers' knowledge of their pension coverage, data on workers alone are not sufficient for assessing that knowledge. The linked SCF-PPS data provide an unusual opportunity to determine the extent of worker knowledge. At the same time, the process of linking the two data sets was often not straightforward: because information provided by workers or employers was sometimes incomplete or inconsistent, it took considerable effort to match some of the records, and those for which a reasonable match could not be made had to be 
excluded from the analysis. Nonetheless, the remaining observations provided an ample subset of the relevant sample, and the use of legal documents on pension plans ensured a high data quality on the pension-provider side.

We found that workers, in general, were fairly well informed about the type of pension coverage they had, as well as about some of the basic features of their plans. While no characteristic stands out as a predictor of whether or not individuals know the details of their pension plans, there was some evidence that workers in large firms are better informed. Comparing these findings to Mitchell's (1988) earlier results from the 1983 SCF, workers' knowledge about their pension coverage seems to have improved somewhat. ${ }^{11}$ However, the results indicate that a large share of workers still had limited knowledge about some more detailed features of defined contribution plans. Since the 1989 survey, there has been a further increase in workers covered by 401(k)-type plans. The retirement income from such plans depends on how much is contributed as well as how the investments are allocated. Many of these decisions are placed on the workers, and knowledge about the plan features is crucial in planning for retirement. Workplace education may be an important tool in contributing to workers' understanding of their pension coverage.

11. It is also possible that the restructuring of the pension questions in the 1989 SCF reduced misreporting on the part of respondents. 
Table 1: Pension Plan Data

Before linking reports by firms and households:

\begin{tabular}{|c|c|c|r|r|}
\hline \multicolumn{2}{|c|}{ Number of Plans reported by: } & $\begin{array}{c}\text { Number of } \\
\text { plans reported } \\
\text { by firm }\end{array}$ & $\begin{array}{r}\text { Number of } \\
\text { firms }\end{array}$ & Percent of plans \\
\hline Firm & Respondent & & 298 & 44.9 \\
\hline 1 & 1 & 298 & 40 & 12.1 \\
2 & 2 & 80 & 2 & 0.9 \\
\hline 3 & 3 & 6 & 118 & 17.8 \\
1 & 2 & 118 & 22 & 3.4 \\
\hline 2 & 1 & 22 & 49 & 14.8 \\
2 & more than 2 & 14 & 7 & 2.1 \\
\hline 3 or more & different than 3 & 27 & 8 & 4.1 \\
\hline Total number of plans: & 663 & 554 & 100.0 \\
\hline
\end{tabular}

After linking reports by firms and households:

\begin{tabular}{|c|c|c|r|}
\hline \multicolumn{2}{|c|}{ Number of Plans reported by: } & $\begin{array}{c}\text { Number of } \\
\text { plans in sample: }\end{array}$ & Percent of plans \\
\hline Firm & Respondent & & 49.5 \\
\hline 1 & 1 & 298 & 13.3 \\
3 & 2 & 80 & 1.0 \\
\hline 1 & 3 & 6 & 19.6 \\
1 & 2 & 118 & 3.7 \\
\hline 2 & 3 or more & 22 & 8.1 \\
2 & 1 & 49 & 2.3 \\
\hline 3 or more & different than 3 & 14 & 2.5 \\
\hline Total number of plans: & 602 & 100.0 \\
\hline
\end{tabular}

Data: Merged 1989 Survey of Consumer Finances and 1989 Pension Provider Survey 
Table 2: Agreement between Employer and Employee on Pension Plan Characteristics

\begin{tabular}{|l|r|r|}
\hline & Percent Agreeing & Percent \\
& Don't Know \\
\hline Type of plan & 77.5 & 1.2 \\
All & 76.0 & 1.4 \\
Employer has DB-plan & 80.7 & 0.5 \\
Employer has DC-plan & & \\
\hline If Agreement on type of plan: & & 0.3 \\
Those with Defined Benefit plan: & 77.6 & 3.8 \\
Employee contribution & 81.6 & \\
Portability & & 7.3 \\
Those with Defined Contribution & & 1.7 \\
plan: & 65.1 & 1.2 \\
Type of DC plan & 74.0 & 7.8 \\
Employee contribution & 86.1 & 10.8 \\
Employer contribution & 30.7 & $\mathrm{n} / \mathrm{a}$ \\
Can withdraw funds & 63.7 & \\
Can borrow funds & 65.9 & \\
Investment options* & & \\
& & \\
\hline
\end{tabular}

* The firm data, investment options are only available for plans where the employee can direct the investments.

Data: Merged 1989 Survey of Consumer Finances and 1989 Pension Provider Survey. 
Uे

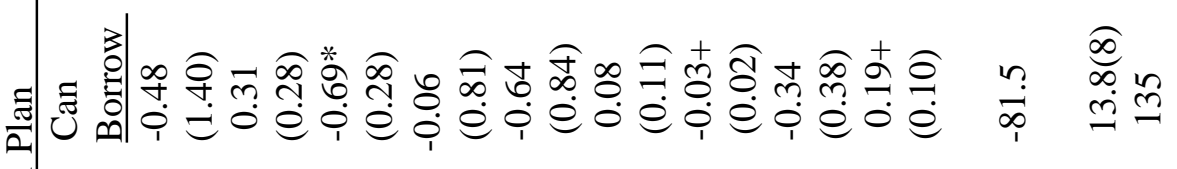

政

至

$\dot{0} \cdot \frac{0}{\Xi}$

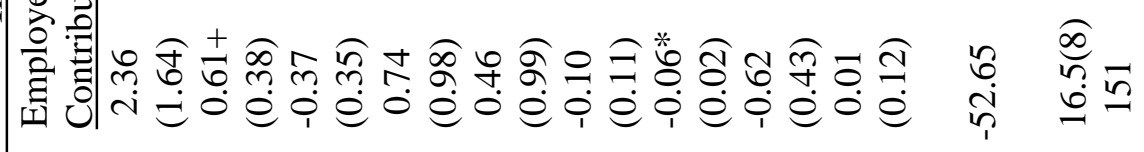

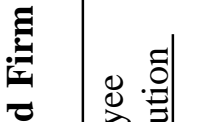

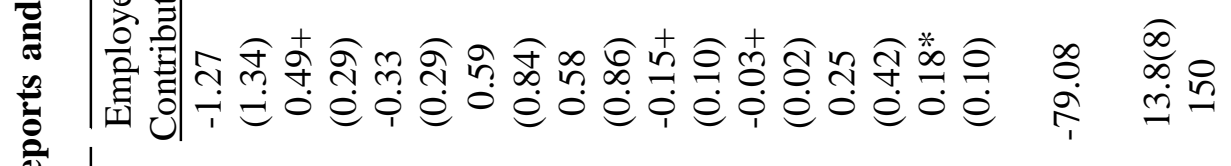

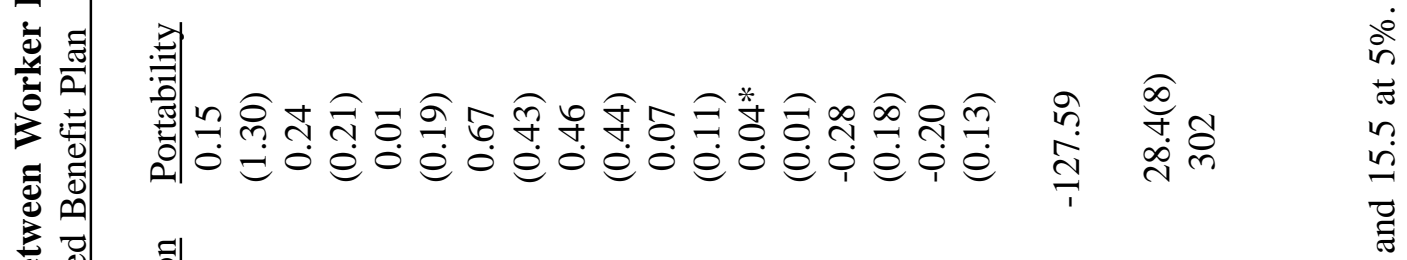

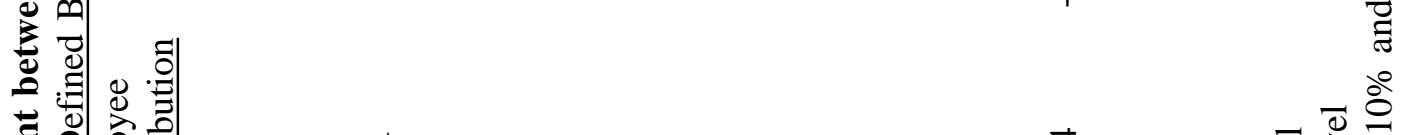

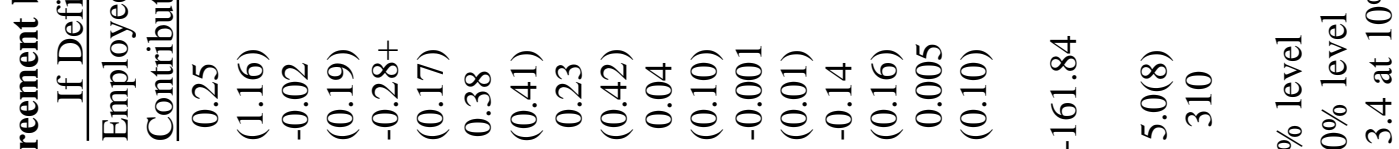

bo

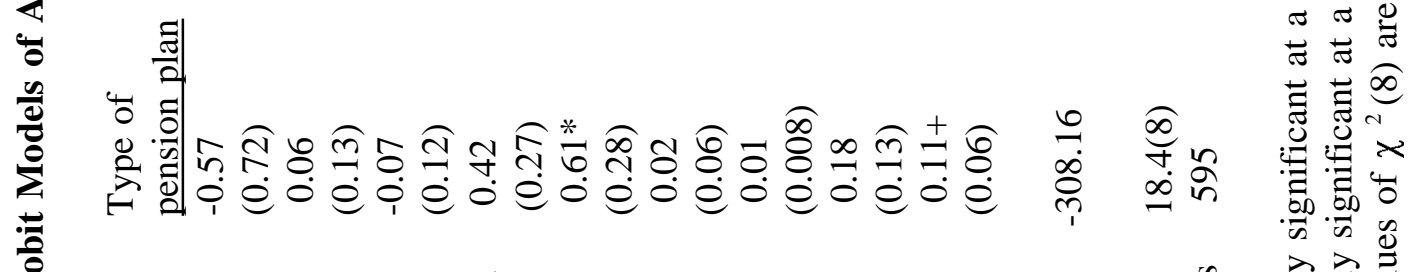

光

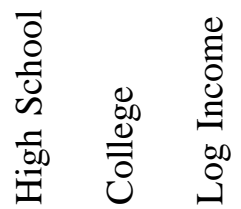

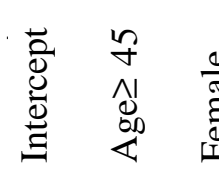

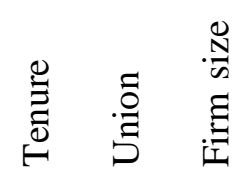

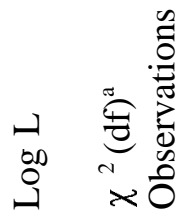

츨 


\section{$\underline{\text { References }}$}

Bernheim, B. Douglas (1988). "Social Security Benefits: An Empirical Study of Expectations and Realizations," In Issues in Contemporary Retirement, edited by Rita RicardoCampbell and Edward P. Lazear. Stanford: Hoover Institution Press. (1994). "The Determinants of and Consequences of Financial Illiteracy," Mimeo, Princeton University.

Employee Benefit Research Institute (1996). "Participation Education: Actions and Outcomes," EBRI Issue Brief, No. 169 (January), Washington, DC.

Hinz, Richard P., John A. Turner, and Phyllis A. Fernandez, eds. (1994). "Pension Coverage Issues for the 90's," U.S. Department of Labor, Washington DC..

Mitchell, Olivia S. (1988). "Worker Knowledge of Pension Provisions," Journal of Labor Economics, 6: 21-39.

Mitchell, Olivia S., and Andrews, Emily (1981). "Scale Economies in Private Multiemployer Pension Plans," Industrial and Labor Relations Review 34 (July): 522-30.

Kennickell, Arthur B, and Starr-McCluer, Martha (1994). "Changes in Family Finances from 1989 to 1992: Evidence from the Survey of Consumer Finances," Federal Reserve Bulletin, 80 (October): 861-882. 